\title{
3D printing guide plate for accurate hemicortical bone tumor resection in metaphysis of distal femoral: a technical note
}

Hongwei Wu(D, Shuo Yang, Jianfan Liu, Linqin Li, Yi Luo, Zixun Dai, Xin Wang, Xinyu Yao, Feng Zhou and Xian'an Li

\begin{abstract}
Background: Surgical resection and reconstruction for low-grade bone sarcoma in the metaphysis of the distal femur remain challenging. We hypothesized that 3D printing osteotomy guide plate could assist to accurately resect the tumor lesion and save the joint function.

Methods: From January 2017 to August 2019, five patients diagnosed with low-grade bone sarcoma in the metaphysis of the distal femur were treated with hemicortical resection using 3D printing guide plate. Autologous bone graft was inactivated in a high-temperature water bath and re-implanted in situ fixed with plate and screw. Patients were followed up from 17 to 33 months. The Musculoskeletal Tumor Society Score was used to evaluate the joint function. X-ray was used to evaluate the bone union.

Results: One patient was paracorticular osteosarcoma, and four cases had highly differentiated chondrosarcoma. All cases were involved in the metaphysis of the distal femur. Patients were followed up from 13 to 33 months, with an average of 23.6 months. There was neither post-operation infection, internal fixation loosening, nor fracture occurrence in any of the patients. The Musculoskeletal Tumor Society Score averaged at 28.1, while the International Society of Limb Salvage imaging score examination averaged 89.8\%.

Conclusions: Here, we demonstrate that the 3D printing osteotomy guide plate-assisted hemicortical bone resection is a beneficial strategy to effectively resect the primary low-grade malignant bone tumors in the metaphysis of the distal femur and retained satisfied joint function.
\end{abstract}

Keywords: Bone resection, Metaphysis of the distal femur, Reconstruction, Devitalization, 3D guide plate, Hemicortical resection

\section{Background}

Paracortical osteosarcoma and highly differentiated chondrosarcoma are the most prevalent low-grade malignant primary bone tumors [1, 2]. Hemiexcision of the tumor bone with inactivated tumor bone replantation is a

\footnotetext{
* Correspondence: lixianan@hnca.org.cn

Department of Orthopedics, Hunan Cancer Hospital and The Affiliated Cancer Hospital of Xiangya School of Medicine, Central South University, 283 Tongzipo Road, Changsha, Hunan 410013, People's Republic of China
}

valuable surgical procedure for low-grade malignant bone tumors [3-5]. However, it has been reported that this procedure has several complications, such as inadequate margins, infection, and fractures of the host bone [6]. Especially in the metaphysis of the long bone, unintended excision margin usually resulted in dysfunction of the adjacent joint [5]. For safe surgical boundaries, the hemibone resection strategy should retain as more normal bone tissue as possible, thus providing favorable conditions for the

C C The Author(s). 2021 Open Access This article is licensed under a Creative Commons Attribution 4.0 International License, which permits use, sharing, adaptation, distribution and reproduction in any medium or format, as long as you give appropriate credit to the original author(s) and the source, provide a link to the Creative Commons licence, and indicate if changes were made. The images or other third party material in this article are included in the article's Creative Commons licence, unless indicated otherwise in a credit line to the material. If material is not included in the article's Creative Commons licence and your intended use is not permitted by statutory regulation or exceeds the permitted use, you will need to obtain permission directly from the copyright holder. To view a copy of this licence, visit http://creativecommons.org/licenses/by/4.0/ The Creative Commons Public Domain Dedication waiver (http://creativecommons.org/publicdomain/zero/1.0/) applies to the data made available in this article, unless otherwise stated in a credit line to the data. 
reconstruction of the bone defects for the rapid postoperative recovery [6-8].

Recently, 3D printing technology has been extensively used in the medical field [9-12]. For instance, establishing tumor models in vitro helps doctors understand tumor shapes and the adjacent tissues from multiple perspectives and also identify lesion locations and surgical risks. Additionally, the technology has been applied in 3D printing implants through in vivo studies to assist in determining surgical boundaries [13-15]. In this technical note, we describe the technique using 3D printed osteotomy guide plate for accurate hemiexcision. Shortterm follow-up results and shortcomings of this technique were also discussed.

\section{Methods}

Five patients with tumor mass in the distal metaphysis of the femur were selected to receive this operation from January 2017 to August 2019 (Table 1). There were four cases of posterior femoral tumor and one case of lateral femoral tumor. One patient was diagnosed with paracortical osteosarcoma, and the other four were diagnosed with chondrosarcoma. The diagnosis was taken via biopsy and reported by a specialized pathologist. There were one male and four females. The minimum age of the patients was 11 , the maximum 65 , and the mean age was 29.8 years old.

$\mathrm{X}$-ray, thin-layer enhanced three-dimensional $\mathrm{CT}$, and MRI were conducted for the tumor site examination upon admission (Fig. 1). The patients were informed of the feasibility of this operation based on the comprehensive assessment of their medical history, clinical signs, and imaging manifestations.

Simultaneously, we retrieved the enhanced CT scan data of the bone tumor sites and used the Mimics software (Materialise's interactive medical image control system, USA) to extract and reconstruct the 3D CT scan data, to highlight the location and size of the tumor lesions, and to print the 3D tumor bone model. We used the Mimics software to mark the tumor resection scope and the osteotomy model (Fig. 2a-c). Afterward, the doctor determined the safe boundary of tumor resection. For low-grade malignant tumors, $2 \mathrm{~cm}$ outside the tumor was generally selected as the safe boundary of resection. The osteotomy guide plate was then developed to facilitate the determination of the resection boundary and efficacy of accurate osteotomy during the operation (Fig. 2d, e). The tumor bone model and the guide plate were both printed with poly-L-lactide acid (PLLA) using the melting extrusion method.

During the operation, we adopted general anesthesia and optimal surgical approaches based on the different tumor sites. For the posterior femoral tumor, dual medial and lateral incisions were adopted to completely expose the operative field [4]. The surface of the mass was generally covered with a fibrous capsule. The capsule was not cut directly, while the normal tissue outside the capsule was separated to the cortical surface of the bone. The vessels close to the tumor were separated apart from the mass and protected carefully. The periosteum stripper stripped the adjacent soft tissue attached to the bone about 3-5 $\mathrm{cm}$ up and down. The osteotomy guide plate was then covered on the surface of the tumor bone and fixed by two K-wires (Fig. 3a, b), and the pendulum sawing osteotomy along the guiding plate was applied to remove the whole tumor bone. During the process of osteotomy, the saw should be maintained accurately along the groove to prevent the breakage of the guide plate. We scraped the visible tumor bone tissue using the curettage and retained the cutting edge for routine disease examination. We treated the remaining bone tissue using normal saline at $70{ }^{\circ} \mathrm{C}$ for $30 \mathrm{~min}$ to inactivate the tumor cells in the bone tissue (Fig. 3c, d). Subsequently, the inactivated bone tissue was transplanted back to the bone defect site, and the appropriate length of the screw and bone plate was selected to fix the inactivated bone and the adjacent normal bone tissue (Fig. 3e, f).

At 3, 6, 12, and 24 months after the operation, we performed regular follow-up for X-ray to check the bone graft situation and the abdominal B-ultrasound and chest CT to assess whether there was distant metastasis. We adopted the American Society for bone tumors (Musculoskeletal Tumor Society (MSTS)) function scoring system to score [16] the limb function after the reconstructive surgery. We also used the international limb-salvage association (International Society of Limb Salvage (ISOLS)) imaging scoring system for the evaluation of the patients with postoperative radiographic

Table 1 Clinical characteristics of patients who received hemicortical resection and reconstruction

\begin{tabular}{lllllll}
\hline No & Age/gender & Diagnosis & Site & Resected bone $(\mathbf{c m})$ & \% of cortical circumference & Fixation \\
\hline 1 & $11 / F$ & PO & Femur & 11 & 40 & \\
2 & $37 / M$ & CS & Femur & 9 & 40 & 30 \\
3 & $17 / F$ & CS & Femur & 5 & 50 & $P+S$ \\
4 & $65 / F$ & CS & Femur & 15 & 30 & $P+S$ \\
5 & $19 / F$ & CS & Femur & 13 & $P+S$ \\
\hline
\end{tabular}

$P O$ paracortical osteosarcoma, $C S$ chondrosarcoma, $P+S$ plate and screw 

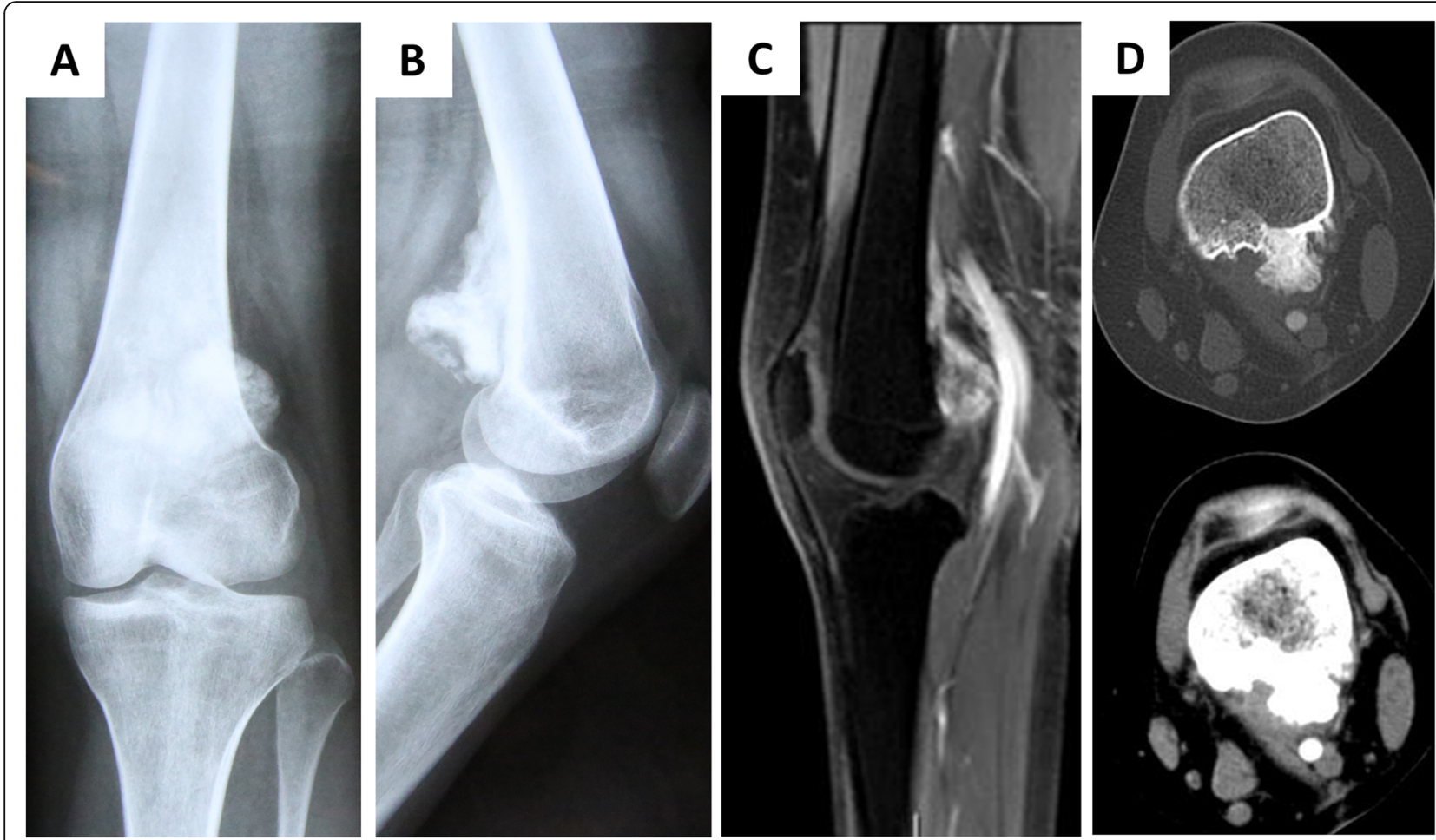

Fig. 1 Image features of chondrosarcoma in the metaphysis of the distal femur. Nineteen-year-old female patient with chondrosarcoma. $\mathbf{a}$, $\mathbf{b}$ Xray indicated a large osteogenic bone lesion at the posterior femur of the left leg. $\mathbf{c}$ MRI enhanced scan showing the lesion was closely adjacent to the popliteal vessels. $\mathbf{d}$ Cross-section of CT scan demonstrated that the lesion was close next to the vessels

images regarding the bone healing at the cutting surface, the graft bone changes, the stability of the internal fixation, and the joint mobility. Lastly, the percentage evaluation result was obtained by dividing the sum of the integral of each item by the full score.

\section{Results}

All patients received a complete resection of the bone tumor. In particular, the longest inactivated bone tumor after resection was $17 \mathrm{~cm}$, while the shortest bone tumor was $9 \mathrm{~cm}$, with an average of $13.8 \mathrm{~cm}$. The excised bone accounted for $30-50 \%$ of the diameter of the diaphysis, with an average of $38 \%$. Notably, postoperative pathological analysis was consistent with the biopsy pathology results.

Particularly, there were four cases with a giant lesion very close to the posterior tibial vessels and femur condyles (see supplemental materials). Besides the vessels were delicately separated from the lesion, the lesion was resected intactly using this method (Fig. 3c, d). The inactivated bone was then re-implanted into the defect site. The fixation was stable, and the bone graft was well fixed (Fig. 3e, f). Additionally, no residual tumor at the postoperative incision edge was noted in any patient based on the pathological examination. Overall, the pain score at 3 months after surgery was $1-4$ points, averaging 2.2 points. All patients were followed up after surgery for 17-33 months, and the median follow-up time was 23.6 months. The highest percentage of the resected bone was $50 \%$ of the cortical circumference, and the lowest one was $30 \%$. Importantly, none of the patients developed loosening or fracture of the internal fixation and femur fracture from the post-operation $\mathrm{X}$ ray examination. The case in this technical note exhibited bone union 24 months post-operation (Fig. 4c, d).

Patients were suggested to walk cautiously with the aid of crutches 3 months after surgery. During the last follow-up, all patients exhibited satisfactory limb function and good joint activity. Representative images and videos were shown in supplementary materials. The MSTS score averaged at 28.1, while the ISOLS imaging score examination averaged $89.8 \%$. Of note, there was no postoperative recurrence, internal fixation loosening and fracture, bone mass displacement, and metastasis in all patients (Table 2).

\section{Discussion}

In this technical note, we introduced an effective method to resect the low-grade bone tumor in the metaphysis of distal femur intactly. Conventional hemicortical excision or piece meal resection usually resulted in residual tumor or fracture. The resection plane could not be controlled delicately. Especially in the posterior part of the 


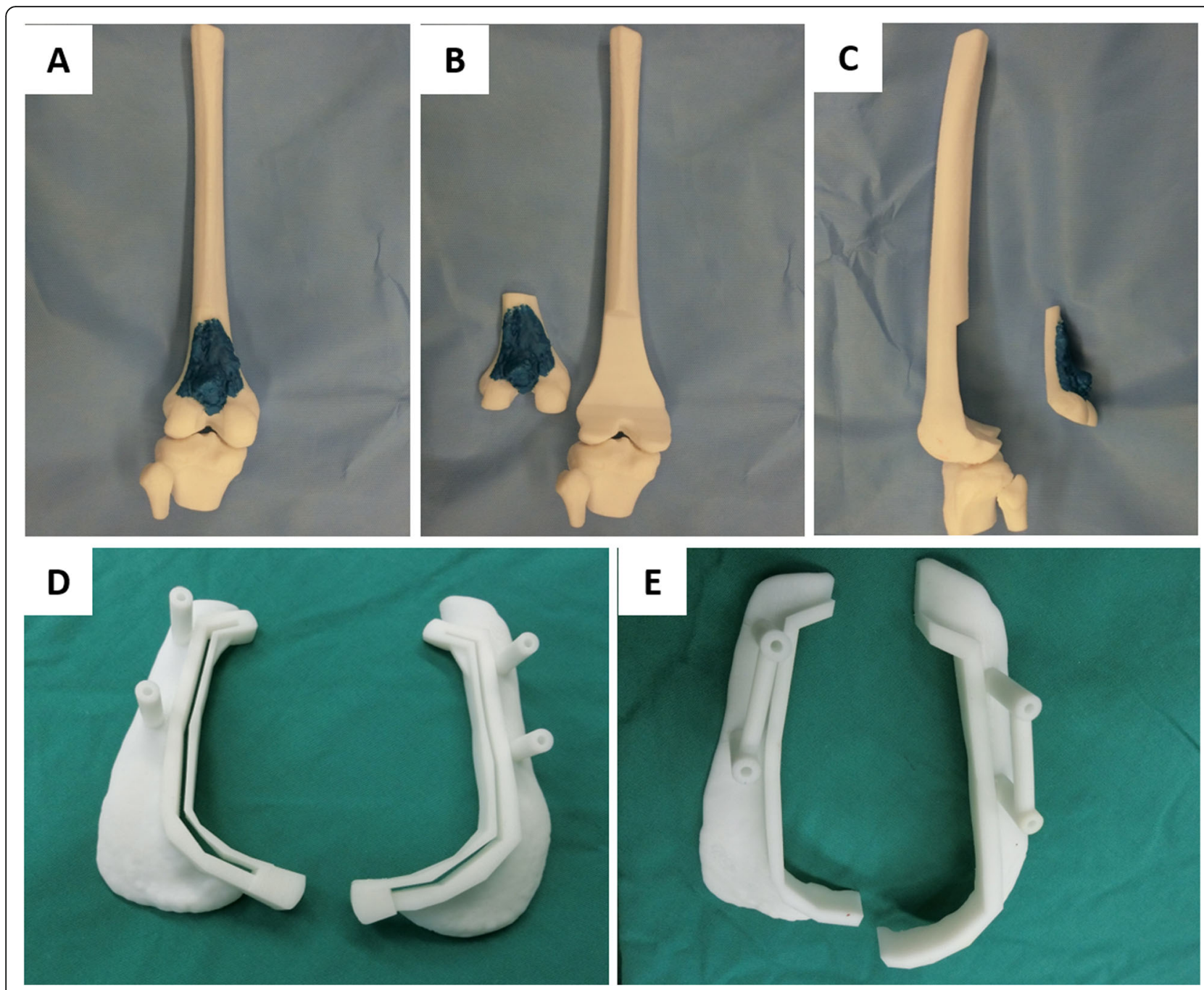

Fig. 2 3D printed bone tumor model and guide plate. a 3D printed bone tumor model. b, c The planned excision boundary of the lesion. $\mathbf{d}$, e 3D printed bone resection guide plate with guide pin holes

distal femur, the vessels usually interfere with the exposure of the surgical field, making it more difficult to operate. Furthermore, excision of large segments of the joint requires extensive joint reconstruction. Allogenic bone graft or cement for this reconstruction leads to reduced joint function and a similar risk of infection to other internal plants $[17,18]$. Therefore, despite its limited indications, hemicortical resection followed by inactivation and replantation is recognized and applied by many scholars $[6-8,19]$. Campanacci et al. were the first to report the application of hemiectomy in bone tumor surgery [20]. Also, some scholars have used hemiexcision for the surgical treatment of high-grade osteosarcoma. It has been noted that it is suitable for eccentric bone tumors, but its long-term effects remain elusive [19]. In particular, hemiexcision is more predominantly used for low-grade malignant tumors $[3,4,7,21,22]$. In this study, all the patients were of low-grade malignant tumors. The benefits of hemiexcision include tumor resection can be expanded, preserves the stability and integrity of adjacent joints, enhances the residual normal bone mechanics using autologous or allogeneic bone grafting, matches the size of the original bone defect accurately, and has no risk of disease transmission. Of note, the initial safety margin of tumor resection is crucial to the treatment effect. Factors such as tumor location, shape, and size pose challenges to the effective application of hemibone resection. Due to the irregular shape of the tumor, and the restriction of the surgical field of view, surgeons may have to make certain plan changes during the osteotomy procedure. This may lead to the unsafe tumor resection border and the recurrence 

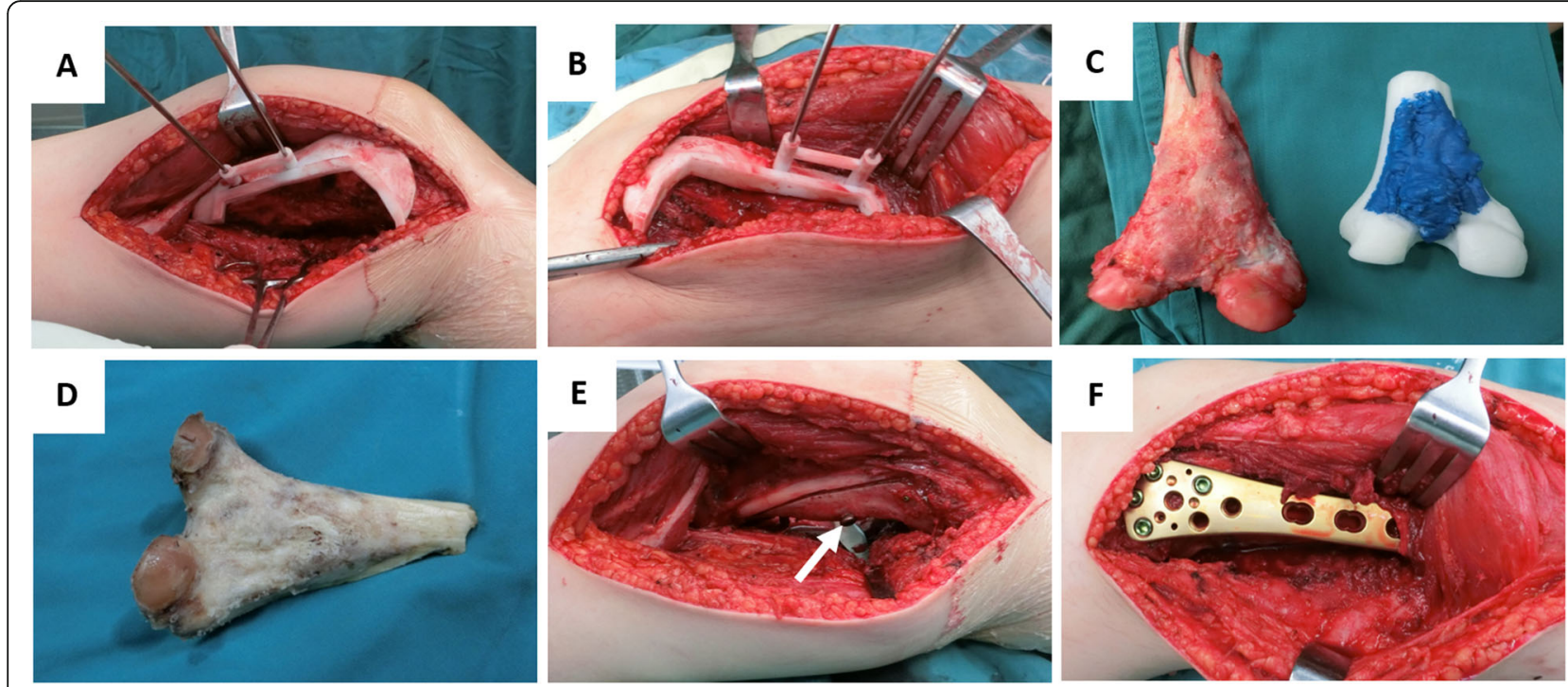

Fig. 3 Operation procedure for the resection of the tumor. a 3D printing guide plate fixed by two K-wires in the medial side. $\mathbf{b} 3 \mathrm{D}$ printing guide plate fixed by two K-wires on the lateral side. $\mathbf{c}$, $\mathbf{d}$ The tumor block was resected intactly and deactivated. e The deactivated bone graft was reimplanted orthotopically. $\mathbf{f}$ The bone graft was fixed by screw and plate

of residual tumor. For malignant bone tumors at the distal end of the posterior femur, it is difficult to preserve the blood vessels as well as joint function [4].

In the past, no method was available to make threedimensional measurements on the tumor before surgical resection. However, computer technology has enabled this measurement to be made, thus achieving a higher matching degree between the tumor defect removed and the bone graft reconstructed [23, 24]. Another method used to accurately remove a tumor from the bone is the surgical navigation robot, but this tool is expensive and not readily available in ordinary hospitals. Recently, 3D digital reconstruction and 3D printing of osteotomy guide plate technology have improved osteotomy for hemibonectomy of bone tumors. The 3D reconstruction of the bone tumor is achieved using a three-dimensional
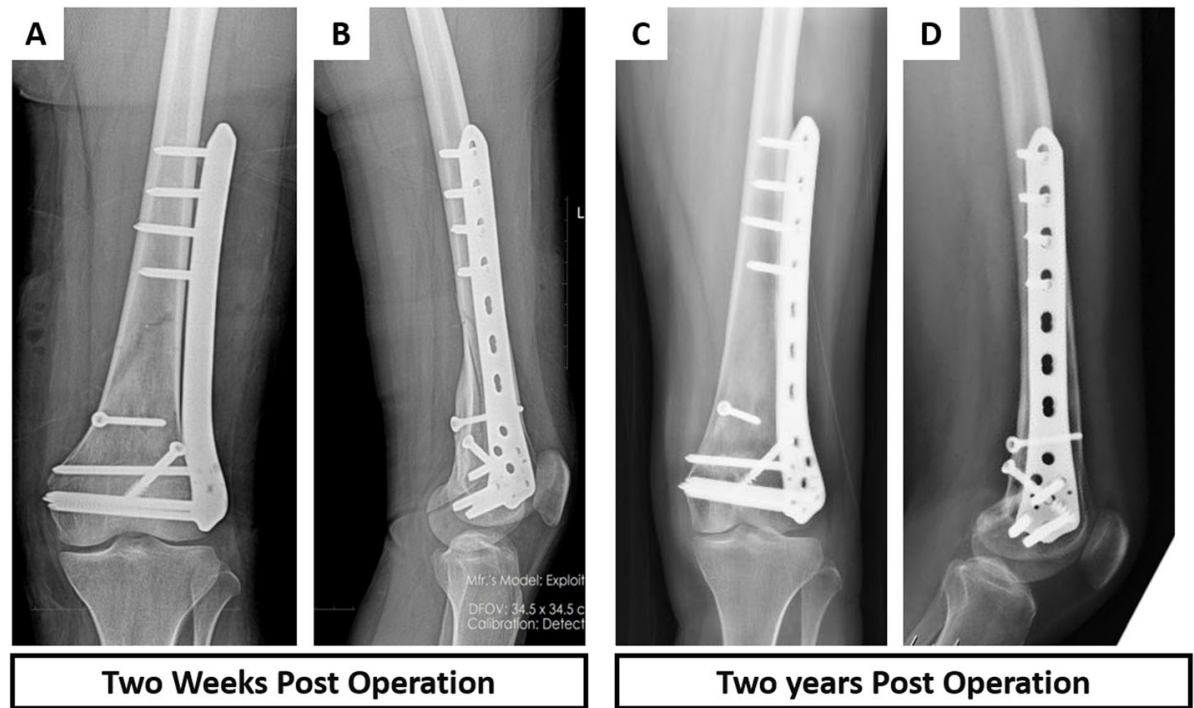

Fig. 4 Follow-up images of the representative patient. $\mathbf{a}$, $\mathbf{b}$ X-ray images 2 weeks post-operation showing that the gap was clear between the bone block and the host bone. $\mathbf{c}$, $\mathbf{d}$ X-ray images 24 months post-operation 
Table 2 Clinical outcome of five patients with hemicortical resection and reconstruction

\begin{tabular}{|c|c|c|c|c|c|c|c|c|}
\hline No. & $\begin{array}{l}\text { Age/ } \\
\text { gender }\end{array}$ & $\begin{array}{l}\text { Complications/fixation } \\
\text { failure }\end{array}$ & $\begin{array}{l}\text { Pain } \\
\text { score }\end{array}$ & $\begin{array}{l}\text { FWB } \\
\text { (months) }\end{array}$ & $\begin{array}{l}\text { Follow-up } \\
\text { (months) }\end{array}$ & $\begin{array}{l}\text { MSTS } \\
\text { Score }\end{array}$ & $\begin{array}{l}\text { ISOLS } \\
\text { Score }\end{array}$ & $\begin{array}{l}\text { Recurrence/ } \\
\text { metastasis }\end{array}$ \\
\hline 1 & $11 / F$ & Incision exudation/N & 4 & 3 & 18 & 27 & 83 & $\mathrm{~N} / \mathrm{N}$ \\
\hline 2 & 37/M & Wound effusion/N & 4 & 3 & 17 & 26 & 78 & $\mathrm{~N} / \mathrm{N}$ \\
\hline 3 & $17 / F$ & None/N & 1 & 3 & 33 & 27 & 91 & $\mathrm{~N} / \mathrm{N}$ \\
\hline 4 & $65 / F$ & None/N & 2 & 3 & 26 & 29 & 93 & $N / N$ \\
\hline 5 & $19 / \mathrm{F}$ & Wound effusion/N & 1 & 3 & 24 & 29 & 94 & $\mathrm{~N} / \mathrm{N}$ \\
\hline
\end{tabular}

FWB full weight-bearing, MSTS Musculoskeletal Tumor Society, ISOLS International Society of Limb Salvage, $N$ negative

CT scan which transmits the data into a 3D reconstruction software to establish a 3-dimensional model. This technique reveals the tumor after printing, thus allowing doctors to make a plan for the resection border. The corresponding resection guide plate can be fabricated according to the plan [23]. Theoretically, the safe boundary of osteotomy for this method is more reliable, and the chances of postoperative recurrence are lower. Moreover, with the assistance of the osteotomy guide plate, the time needed for osteotomy localization is relatively shorter, which reduces the operation time and in turn decreases blood loss, thus making it more effective in the rehabilitation of patients. Using the osteotomy guide plate, most of the bone tumor can be removed as a whole, rather than unplanned lumps. After inactivation treatment, the original shape of most of the bone tumor is maintained which creates a very high matching degree with the bone defect site. This ensures good fixation of bone blocks and also shortens the operation time. Overall, this method results in good postoperative recovery and functional recovery.

Previous studies have reported that fractures, infections, and incomplete resection contribute to the development complications of hemiexcision. Specifically, fracture is one of the leading cause (10-18\%) [3, 25]. In 2014, some scholars used computer-assisted surgery to design an allograft bone graft to repair the bone defect of hemibonectomy. They noted that the method achieved resection and reconstruction precisely with less time-consuming and also reduced the incidence of fracture [23]. Therefore, a 3D-printed osteotomy guide plate can be used to perform accurate osteotomy based on the preoperative surgical plan, without any intraoperative or postoperative fractures. Herein, the inactivated bone tissue was transplanted back into the patient perfectly matched with the original bone defect, shortening the time taken to reconstruct the bone defect and adjust the bone mass. Besides, our short-term postoperative follow-up results enumerated no recurrence in all 5 patients. This implies a safe tumor resection boundary. We also achieved accurate R0 resection and successful reconstruction even for adjacent joint lesions, and this perhaps may have contributed to the highly preserved joint function. Functional scores of the affected limbs after surgery were above 24 points in all patients, while patient satisfaction was very high. This finding is consistent with the recent reports by Japanese scholars [26] and also exceeds scores reported in a review by Dutch scholars [6]. Therefore, this surgical approach is effective for the removal of bone tumors and bone reconstruction. High short-term efficacy following inactivation and replantation of hemibone resection for highly malignant bone tumors has been reported [19]. This indicates that it is possible to achieve an effective safe boundary for tumor control. However, the long-term efficacy of our method should be investigated further to confirm these intriguing findings, especially in follow-up studies.

In summary, digital three-dimensional reconstruction is a valuable technique for formulating osteotomy boundary and osteotomy guide plate-assisted osteotomy, which makes hemibone resection more convenient, faster, and reduces the risk of postoperative complications, and lowers the recurrence rate. Furthermore, the method used herein is cheap, reliable, and results in quick recovery. Notably, this is important for reserving the joint function regarding the tumor adjacent to the joint. Despite these benefits, we acknowledge that hemiexcision has its inherent limitations. Among them is the risk of postoperative recurrence and insecure surgical boundaries. The follow-up period for patients in this study is relatively short, and thus, a longer follow-up duration is needed to test the long-term effect of this surgical method. Also, the current digital threedimensional reconstruction does not accurately identify the tumor tissue, making it difficult to achieve intelligent grasp recognition. Therefore, manual intervention is required to determine the tumor boundary. We believe that with further advancements in imaging, digital technology, and artificial intelligence, these problems will be gradually solved, and hemibonectomy will yield better therapeutic effects.

\section{Conclusions}

The 3D printing guiding plate offered a useful approach for completely resecting low malignant metaphyseal 
bone tumors. The joint function is excellent, and the recurrence rate is low for short-term follow-up. The technique saves time and decreases bleeding during the operation. The cost of this technic is affordable and worthy to be applied to this kind of disease.

\section{Abbreviations}

FWB: Full weight-bearing; MSTS: Musculoskeletal Tumor Society; ISOLS: International Society of Limb Salvage; N: Negative; PO: Paracortical osteosarcoma; CS: Chondrosarcoma; P+S: Plate and screw

\section{Supplementary Information}

The online version contains supplementary material available at https://doi. org/10.1186/s13018-021-02374-w.

Additional file 1. Case 1. Case 2. Case 3. Case 4. Case 5 po 3 months. Additional file 2. Supplement figure.

\section{Acknowledgements}

The authors thank Dr. Jerry for the language editing and revision.

\section{Authors' contributions}

HW wrote the manuscript and analyzed the data. XL conceived the study and revised the manuscript. Other authors contributed to the patient information collection and operations. All authors read and approved the final manuscript and agreed to be accountable for all aspects of the work.

\section{Funding}

The study was supported by the Project of Natural Science Foundation of Hunan Province (No.2018JJ2243), Hunan Provincial Health Commission's Scientific Research Program (No. C20180690), and Project of Changsha Science and Technology Bureau (kq1907121).

\section{Availability of data and materials}

All the data and materials are available from the corresponding author upon reasonable request.

\section{Declarations}

\section{Ethics approval and consent to participate}

Ethics approval was not applicable in this study. Written informed consent for participation was obtained from all patients before the start of the therapy.

\section{Consent for publication}

Written informed consent was required from patients in case 9 for the publication of this manuscript. Copies of the written consent are available for review by the Editor-in-Chief of the journal.

\section{Competing interests}

The authors declare that they have no competing interests.

Received: 31 January 2021 Accepted: 21 March 2021

Published online: 28 May 2021

\section{References}

1. Harper K, Sathiadoss P, Saifuddin A, Sheikh A. A review of imaging of surface sarcomas of bone. Skelet Radiol. 2020.

2. Liu S, Zhou X, Song A, Huo Z, Wang Y, Liu Y. Surgical treatment of chondrosarcoma of the sacrum with cement augmentation: a case report. Medicine. 2019;98(50):e18413. https://doi.org/10.1097/MD.0000000000018413.

3. Deijkers RL, Bloem RM, Hogendoorn PC, Verlaan JJ, Kroon HM, Taminiau AH. Hemicortical allograft reconstruction after resection of low-grade malignant bone tumours. J Bone Joint Surg Br. 2002;84(7):1009-14. https://doi.org/1 0.1302/0301-620X.84B7.0841009.

4. Lewis VO, Gebhardt MC, Springfield DS. Parosteal osteosarcoma of the posterior aspect of the distal part of the femur. Oncological and functional results following a new resection technique. J Bone Joint
Surg Am. 2000;82(8):1083-8. https://doi.org/10.2106/00004623-2 $00008000-00003$

5. Pezzillo F, Maccauro G, Nizegorodcew T, Rossi B, Gosheger G. Resection of parosteal osteosarcoma of the distal part of the femur: an original reconstruction technique with cement and plate. Sarcoma. 2008;2008:763056.

6. Bus MP, Bramer JA, Schaap GR, Schreuder HW, Jutte PC, van der Geest IC, et al. Hemicortical resection and inlay allograft reconstruction for primary bone tumors: a retrospective evaluation in the Netherlands and review of the literature. J Bone Joint Surg Am. 2015;97(9):738-50. https://doi.org/10.21 06/JBJS.N.00948.

7. Liu T, Liu ZY, Zhang Q, Zhang XS. Hemicortical resection and reconstruction using pasteurised autograft for parosteal osteosarcoma of the distal femur. Bone Joint J. 2013;95-B(9):1275-9. https://doi.org/10.1302/0301-620X. 95B9.31433.

8. Lenze U, Kasal S, Hefti F, Krieg AH. Non-vascularised fibula grafts for reconstruction of segmental and hemicortical bone defects following meta-/diaphyseal tumour resection at the extremities. BMC Musculoskelet Disord. 2017;18(1):289. https://doi.org/10.1186/s12891-017-1640-z.

9. Maini L, Sharma A, Jha S, Tiwari A. Three-dimensional printing and patientspecific pre-contoured plate: future of acetabulum fracture fixation? Eur J Trauma Emerg Surg. 2018:44(2):215-24.

10. Liang H, Ji T, Zhang Y, Wang Y, Guo W. Reconstruction with 3D-printed pelvic endoprostheses after resection of a pelvic tumour. Bone Joint J. 2017; 99-B(2):267-75. https://doi.org/10.1302/0301-620X.99B2.BJJ-2016-0654.R1.

11. Ma L, Zhou Y, Zhu Y, Lin Z, Chen L, Zhang Y, et al. 3D printed personalized titanium plates improve clinical outcome in microwave ablation of bone tumors around the knee. Sci Rep. 2017;7(1):7626. https://doi.org/10.1038/s41 598-017-07243-3.

12. Lador R, Regev G, Salame K, Khashan M, Lidar Z. Use of 3-dimensional printing technology in complex spine surgeries. World Neurosurgery. 2020; 133:e327-41. https://doi.org/10.1016/j.wneu.2019.09.002.

13. Park JW, Kang HG, Kim JH, Kim HS. The application of 3D-printing technology in pelvic bone tumor surgery. J Orthop Sci. 2021;26(2):276-83.

14. Ma L, Zhou Y, Zhu Y, Lin Z, Wang Y, Zhang Y, et al. 3D-printed guiding templates for improved osteosarcoma resection. Sci Rep. 2016;6(1):23335. https://doi.org/10.1038/srep23335.

15. Wang F, Zhu J, Peng X, Su J. The application of 3D printed surgical guides in resection and reconstruction of malignant bone tumor. Oncol Lett. 2017; 14(4):4581-4. https://doi.org/10.3892/ol.2017.6749.

16. Enneking WF, Dunham W, Gebhardt MC, Malawar M, Pritchard DJ. A system for the functional evaluation of reconstructive procedures after surgical treatment of tumors of the musculoskeletal system. Clin Orthop Relat Res. 1993:286:241-6.

17. Oliva MS, Vitiello R, Cauteruccio M, Pesare E, Rovere G, Meschini C, et al. Cemented versus cementless megaprosthesis in proximal femur metastatic disease: a systematic review. Orthop Rev (Pavia). 2020;12(Suppl 1):8689.

18. Ziranu A, Lillo M, Fantoni M, Maffulli N, Maccauro G. Single dose cefazolin is safe and effective for pre-operative prophylaxis in orthopaedic oncology. J Biol Regul Homeost Agents. 2018;32(6 Suppl. 1):45-9.

19. Chen WM, Wu PK, Chen CF, Chung LH, Liu CL, Chen TH. High-grade osteosarcoma treated with hemicortical resection and biological reconstruction. I Surg Oncol. 2012;105(8):825-9. https//doi.org/10.1002/jso.23005.

20. Campanacci M, Capanna R, Stilli S. Posterior hemiresection of the distal femur in parosteal osteosarcoma. Ital J Orthop Traumatol. 1982;8(1):23-8.

21. Zhang Q, Liu T, Guo $X$, Ling L. Salvage therapy by hemicortical excision and reconstruction for low-grade malignant bone tumour. Zhong Nan Da Xue Xue Bao Yi Xue Ban. 2013;38(7):691-4

22. Gulia A, Puri A, Pruthi M, Desai S. Oncological and functional outcome of periosteal osteosarcoma. Indian J Orthop. 2014;48(3):279-84. https://doi. org/10.4103/0019-5413.132518.

23. Gerbers JG, Ooijen PM, Jutte PC. Computer-assisted surgery for allograft shaping in hemicortical resection: a technical note involving 4 cases. Acta Orthop. 2013;84(2):224-6. https://doi.org/10.3109/17453674.2013. 775045.

24. De Santis V, Burrofato A, D'Apolito R, De leso C, Magarelli N, Maccauro G, et al. Evaluation of accuracy of bone cuts and implant positioning in total knee arthroplasty using patient specific instrumentation. J Biol Regul Homeost Agents. 2017;31(4 suppl 1):51-60.

25. Agarwal M, Puri A, Anchan C, Shah M, Jambhekar N. Hemicortical excision for low-grade selected surface sarcomas of bone. Clin Orthop Relat Res. 2007:459:161-6. https://doi.org/10.1097/BLO.0b013e318059b8eb. 
26. Nakamura T, Fujiwara T, Tsuda Y, Abudu A, Nomoto Y, Takada A, et al. The clinical outcomes of hemicortical extracorporeal irradiated autologous bone graft after tumor resection of bone and soft tissue sarcoma. Anticancer Res. 2019;39(10):5605-10. https://doi.org/10.21873/anticanres.13755.

\section{Publisher's Note}

Springer Nature remains neutral with regard to jurisdictional claims in published maps and institutional affiliations.

Ready to submit your research? Choose BMC and benefit from:

- fast, convenient online submission

- thorough peer review by experienced researchers in your field

- rapid publication on acceptance

- support for research data, including large and complex data types

- gold Open Access which fosters wider collaboration and increased citations

- maximum visibility for your research: over $100 \mathrm{M}$ website views per year

At BMC, research is always in progress.

Learn more biomedcentral.com/submissions 